\title{
UNA MIRADA AL CARNAVAL DESDE LA PERSPECTIVA DE LA ANTROPOLOGÍA SIMBÓLICA DE CLIFFORD GEERTZY LA ANTROPOLOGÍA ESTRUCTURALISTA DE LÉVI-STRAUSS
}

Catalina Bohórquez Mendoza (Universidad Nacional de Colombia)

La cultura, desde la perspectiva de Clifford Geertz y LéviStrauss, es entendida como una "urdimbre" de significados, como un conjunto de "sistemas simbólicos". Esta concepción se ha denominado definición semiótica de la cultura. En estas páginas se intenta edificar una interpretación del carnaval como expresión fundamental de diferentes grupos sociales. Se analiza el carnaval estudiantil de los años 20 y 30 en la ciudad de Bogotá, con el propósito de descifrar su simbología específica y reconocer su sentido, su función social y las transformaciones que efectuó en la comunidad universitaria y la ciudad de Bogotá.

CARNAVAL, ESTUDIANTES, MÚSICA, CULTURA, SIMBÓLICO, UNIVERSIDAD NACIONAL DE COLOMBIA, BOGOTÁ, REVISTA CONTESTARTE.

MENDOZA, Catalina Bohórquez. Una mirada al carnaval desde la perspectiva de la antropología simbólica de Clifford Geertz y la antropología estructuralista de Lévi-Strauss. Textos escolhidos de cultura e arte populares, Rio de Janeiro, v.9, n.1, p. 39-55, mai. 2012. 


\section{A LOOK AT THE CARNIVAL THROUGH THE PERSPECTIVE OF CLIFFORD GEERTZ'S SYMBOLIC ANTHROPOLOGY AND LÉVI- STRAUSS' STRUCTURAL ANTHROPOLOGY}

Catalina Bohórquez Mendoza (Universidad Nacional de Colombia)

Culture, from the perspective of Clifford Geertz and LéviStrauss, is understood as a "fabric" of meanings, as a set of "symbolic systems". This idea was dubbed a semiotic definition of culture and is one of many approaches to understand this concept. We are interested in constructing an interpretation of carnival as a fundamental expression of different social groups. We analyze the students' carnival of the 1920s and 30s in the city of Bogota in order to decipher its specific symbols and recognize its meaning, its social function and the changes it has caused in the university community and in the city of Bogotá.

CARNIVAL, STUDENTS, MUSIC, CULTURE, SYMBOLIC, UNIVERSIDAD NACIONAL DE COLOMBIA, BOGOTA, CONTESTARTE JOURNAL.

MENDOZA, Catalina Bohórquez. Una mirada al carnaval desde la perspectiva de la antropología simbólica de Clifford Geertz y la antropología estructuralista de Lévi-Strauss. Textos escolhidos de cultura e arte populares, Rio de Janeiro, v.9, n.1, p. 39-55, mai. 2012. 


\section{INTRODUCCIÓN}

La noción de cultura es inherente a la reflexión de las ciencias sociales. Éstas la necesitan, de alguna manera, para pensar la unidad de la humanidad en la diversidad sin hacerlo en términos biológicos (CUCHE, 2002, p. 5).

Las discusiones académicas en torno al significado de la noción de cultura han sido extendidas y sus conclusiones diversas. Aún en la actualidad es imposible hablar de un consenso entre las diferentes perspectivas, $y$ los debates parecen interminables. Hoy en día, me atrevo a decir que la palabra cultura se utiliza en diferentes contextos sin el mayor cuidado, se emplea sin más en expresiones como "cultura ciudadana", "cultura ambiental", o como adjetivo en enunciados como "evolución cultural"; estas expresiones, a la luz de estos debates, resultan oscuras e ininteligibles.

Esta dificultad de definición acarrea una problemática bastante importante. Dado que la noción de cultura es central en los análisis antropológicos - como lo afirma Denys Cuche, "es inherente a la reflexión de las ciencias sociales" -, no es fácil entender cómo esta noción puede ser el eje central de diferentes estudios antropológicos e investigaciones de ciencias sociales sin que tenga un significado claro. Es quizás por eso que en los últimos años se dio la aparición de lo que William Sewell (1999, p. 1) denominó "culturamanía": un intento de que los "conceptos" de cultura confluyeran en uno solo; "reducir el concepto de cultura a sus verdaderas dimensiones" (GEERTZ, 2005, p. 19). Así pues, el análisis de esta cuestión remite a amplias discusiones académicas. Por esta razón, en las siguientes páginas solamente me dedico a exponer una pequeña fracción de estas discusiones.

En el presente texto, teniendo en cuenta el debate en torno a la noción de cultura, me centro en la perspectiva de lo que Clifford Geertz y Lévi-Strauss entienden por ella; es decir, en lo que se ha denominado definición semiótica de la cultura en razón de que, desde este punto de vista, ella es entendida como una "urdimbre" de significados (GEERTZ, 2005, p. 20), como un conjunto de "sistemas simbólicos" (LÉVI-STRAUSS, 1979, p. 20).

A partir de la definición semiótica de la cultura, intento edificar una interpretación del carnaval como expresión fundamental de diferentes grupos sociales. El lector se preguntará: ¿por qué el carnaval? He seleccionado esta expresión cultural por su riqueza simbólica y porque, como afirma Gabriel Restrepo (1997), "Desde el punto de vista social es decisivo para estudiar tanto el funcionamiento normal de la sociedad, como la crisis y el caos"; porque es un enjambre de significados, que es lo que considero esencial de la cultura, en lo 
que sigo a Clifford Geertz y Lévi-Strauss. De modo que representa una de esas manifestaciones populares que conviene analizar desde la perspectiva de lo que estos autores entienden por cultura.

Así pues, para acercarme a mi objetivo de presentar el carnaval como un enjambre de significados, analizo un carnaval específico: el carnaval estudiantil de los años 20 y 30 en la ciudad de Bogotá. Mi propósito es descifrar su simbología específica y reconocer su sentido, su función social y las transformaciones que efectuó en la comunidad. Con esto, espero mostrar en las conclusiones cómo un carnaval se convierte en una expresión central de una cultura.

\section{CONCEPTO SEMIÓTICO DE LA CULTURA}

El hombre es un animal inserto en tramas de significación que él mismo ha tejido (GEERTZ, 2005, p. 20).

En su ensayo Descripción densa: hacia una teoría interpretativa de la cultura, Clifford Geertz (2005, p. 19-40) plantea que esta debe entenderse como esa "trama de significación" en la que el hombre se encuentra inmerso. Así pues, el análisis de esta "trama" debe ser equiparado a la lectura de un texto, al análisis de un poema; a un diálogo entre intérprete y un conjunto de símbolos. Comprender la cultura, desde esta perspectiva, no es más que un diálogo en el que ella le habla al sujeto conocedor y este debe tener la capacidad de escucharla y descifrar los mensajes que ella le proporciona. En sus palabras:

Hacer etnografía es como tratar de leer (en el sentido de "interpretar un texto") un manuscrito extranjero, borroso, plagado de elipsis, de incoherencias, de sospechosas enmiendas y de comentarios tendenciosos y además escrito, no en las grafías convencionales de representación sonora, sino en ejemplos volátiles de conducta modelada (GEERTZ, 2005, p. 24).

Así pues, el análisis etnográfico implica descifrar esa urdimbre de significados que se presentan juntos y desglosarlos en detalle, es decir, hacer lo que se entiende como "descripción densa". Cada fenómeno debe poder ser descrito minuciosamente. Se contraponen así el análisis desde el pensamiento racional, que percibe al mundo como un conjunto de causas encadenadas sin más, y el pensamiento hermenéutico, que intenta develar el secreto iniciático (el secreto final de un mundo convertido en un teatro) y ahora, en el proceso de interpretación, transformarlo en fenómeno lingüístico (PAULUS, 1975, p. 23).

Esta "lectura" de la cultura debe ser entendida de manera cuidadosa. El hombre que quiere comprender la cultura entendida como un texto es tocado 
inevitablemente por la "palabra" y debe saber escuchar y cuestionar para que su análisis tenga frutos (GADAMER 1977, p. 553). El etnólogo debe escuchar los mensajes enviados. Pero es importante aclarar que escuchar no es solo registrar las palabras o símbolos, sino que, más bien, es el proceso en el cual, una vez la palabra toca al receptor, este exige respuestas y se integra en la dialéctica del preguntar al ser interpelado. El hombre, como intérprete, debe estar abierto a escuchar y comprender cada detalle de la "trama de significación" en la que se encuentra inmerso; a escuchar atentamente las respuestas y a comprender la palabra que lo alcanza.

Así pues, la tarea del etnólogo, según Clifford Geertz (2005, p. 27), es ampliar ese "discurso humano" que es la cultura. Se dice ampliar porque, más allá del "texto" dado, debe proporcionarse ese valor agregado que es la interpretación, deben describirse "todos los fenómenos de manera inteligible, es decir, densa". La labor del etnógrafo se reduce, entonces, a develar la psiquis colectiva; a interpretar ese conjunto de sistemas simbólicos de una comunidad.

Según esta concepción semiótica, entonces, la cultura es un conjunto de "sistemas en interacción de signos interpretables" (GEERTZ, 2005, p. 27); se habla de sistemas/estructuras culturales, es decir, sistemas de símbolos significativos. En palabras de Geertz (p. 88):

la cultura denota un esquema históricamente transmitido de significaciones representadas en símbolos, un sistema de concepciones heredadas y expresadas en formas simbólicas por medios con los cuales los hombres comunican, perpetúan y desarrollan su conocimiento y sus actitudes frente a la vida.

Siguiendo con la analogía texto-cultura, Lévi-Strauss ofrece una definición de cultura cimentada en el lenguaje que contrapone la cultura a la naturaleza; que opone lo biológico a la posibilidad única que tienen los seres humanos de construir un lenguaje articulado que puede ser traducido a otros lenguajes y que constituye, para los diferentes grupos humanos, la posibilidad de intercambiar hábitos, aptitudes, creencias, entre otras manifestaciones propias.

Aunque la herencia biológica es la que nos permite poseer un lenguaje articulado por medio del cual comunicar y asimilar las demás culturas, es el lenguaje como tal lo que nos diferencia de cualquier otro ser; cada manifestación artística, o religiosa, debe ser entendida a la luz de esta concepción, es decir, como algo que busca comunicar y, desde otra perspectiva, como algo que queremos comprender. Así pues: 
La cultura puede considerarse como un conjunto de sistemas simbólicos que tienen situados en primer término el lenguaje, las reglas matrimoniales, las relaciones económicas, el arte, la ciencia y la religión. Estos sistemas tienen como finalidad expresar determinados aspectos de la realidad física y de la realidad social, e incluso las relaciones de estos dos tipos de realidades entre sí, y las que estos sistemas simbólicos guardan los unos frente a los otros (LÉVISTRAUSS, 1979, p. 20).

Los humanos, según esta perspectiva, poseemos entonces una función única que consiste, grosso modo, en evocar objetos ausentes mediante sustitutos tales como conceptos, signos, símbolos, imágenes mentales, etc., así como los gestos y otros medios que sirven para expresar los pensamientos, emociones y referirse a las cosas que existen.

\section{PENSAR EL CARNAVAL: EL CARNAVAL COMO UN TEXTO}

En carnavales se tapa la cara con ganas de descubrir el alma. El mundo es un carnaval con careta de traidor (Adagio español).

Sin embargo, el hombre, además de ser un homo loquens, animal lingüístico, y un homo simbolicus, animal simbólico, es un animal creador (RIVAS, 2008). Si bien todas sus manifestaciones culturales son formas simbólicas, que se intercambian por medio de una comunicación lingüística, la capacidad creativa también debe destacarse. Es gracias a esta última condición, inherente a los seres humanos, como se logra sobrellevar lo duro de la existencia. En palabras de Nietzsche (2005, p. 248): "la náusea que causa el seguir viviendo es sentida como medio para crear". Es gracias a esta capacidad creativa como el hombre puede sacar del fondo de sí aquello caótico de su existencia y transformar su entorno.

Una manifestación ejemplar de esta capacidad creadora, que brinda al hombre la posibilidad de mantener su existencia, es el carnaval. Su aparición en las sociedades representa aquello gracias a lo cual la vida es digna de ser vivida, es "una intensificación de la vida en un lapso corto de tiempo" (SCHULTZ, apud GONZÁLEZ, 2011, p. 15). El carnaval brinda la posibilidad de ser otro y de liberarse de aquellas máscaras impuestas, cambiándolas por otras. En palabras de Gonzalo Arango (apud montenegro, 2008, § 6): “devora tu individualidad y te arroja en la gran hoguera crepitante donde la danza te purifica hasta alcanzar el éxtasis, la libertad". 


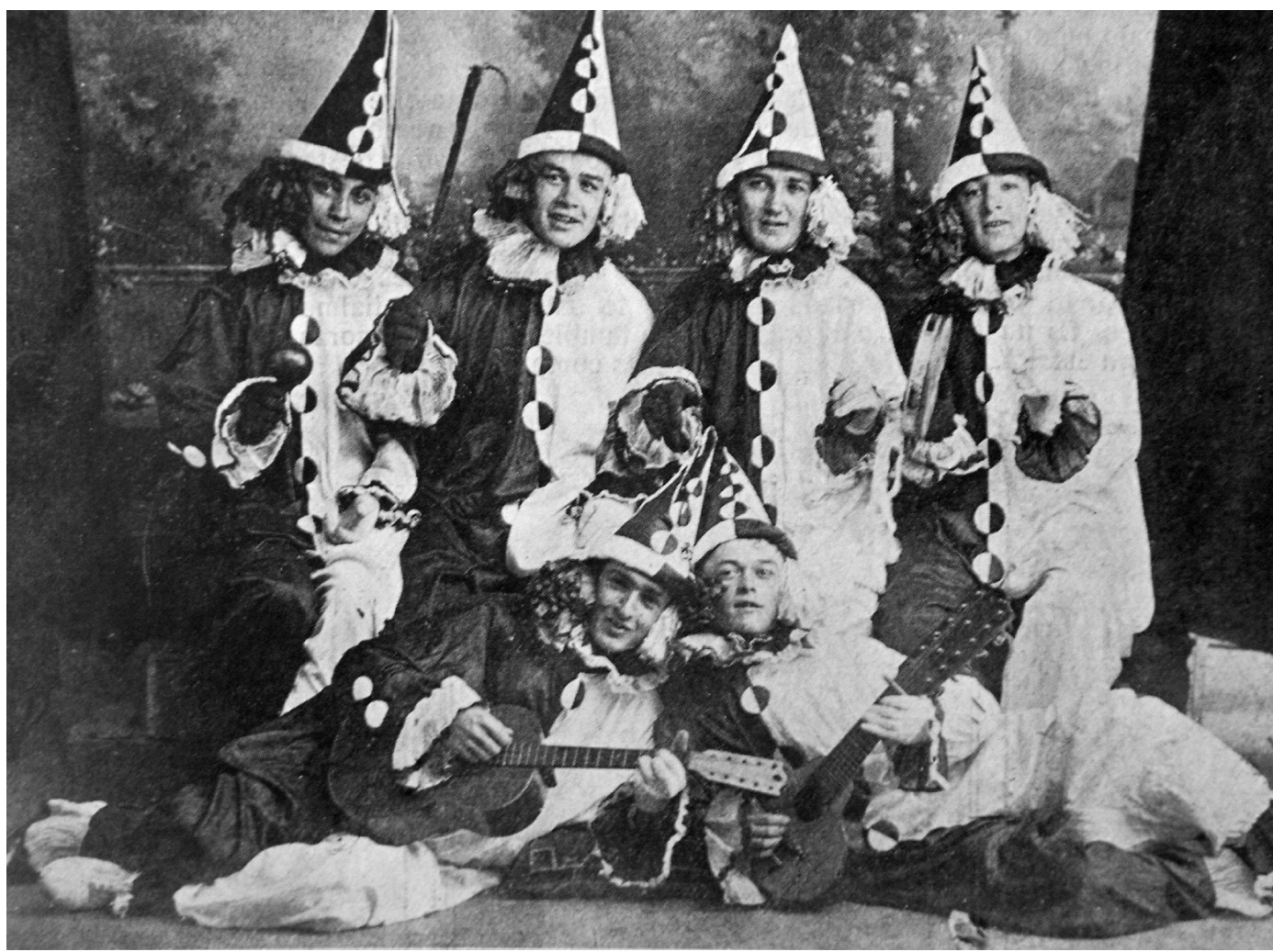

Figura 1: Carnaval Estudiantil de los años 20 y 30 Archivo: Archivos de Intercultura, reproducción fotográfica de Natalia González \&Weimar Ramirez

El carnaval se presenta así como un antídoto contra el estrés y el aburrimiento; genera espacios en los cuales se presentan la diversidad y la pluralidad, se reivindican identidades y se develan las estructuras sociales (GONZÁLEZ, 2011, p. 19). Asimismo, crea una ilusión de unanimidad en la cual todos se presentan como iguales. Y se constituye en un espacio en el cual se induce "a la comunidad para la puesta en escena de la reconciliación y sin ella la vida sería un tronco deforme y cadavérico" (OZOUF, apud GONZÁLEZ, 2011, p. 24).

En este ambiente simbólico surge un nuevo modo de existencia, cada uno crea su nueva identidad a partir de la mezcla de colores, música, disfraces, máscaras y personajes (Figura 1). Y es gracias a esta sobrecarga de significación como se diluye la frontera entre actor y escenario; y, así, "el noble y el villano, el prohombre y el gusano bailan y se dan la mano sin importarles la facha" (Fiesta, Joan Manuel Serrat). Es una fiesta del pueblo y para el pueblo, y expresa por ello los imaginarios de las comunidades (RESTREPO, 1997). En palabras de Jaime 


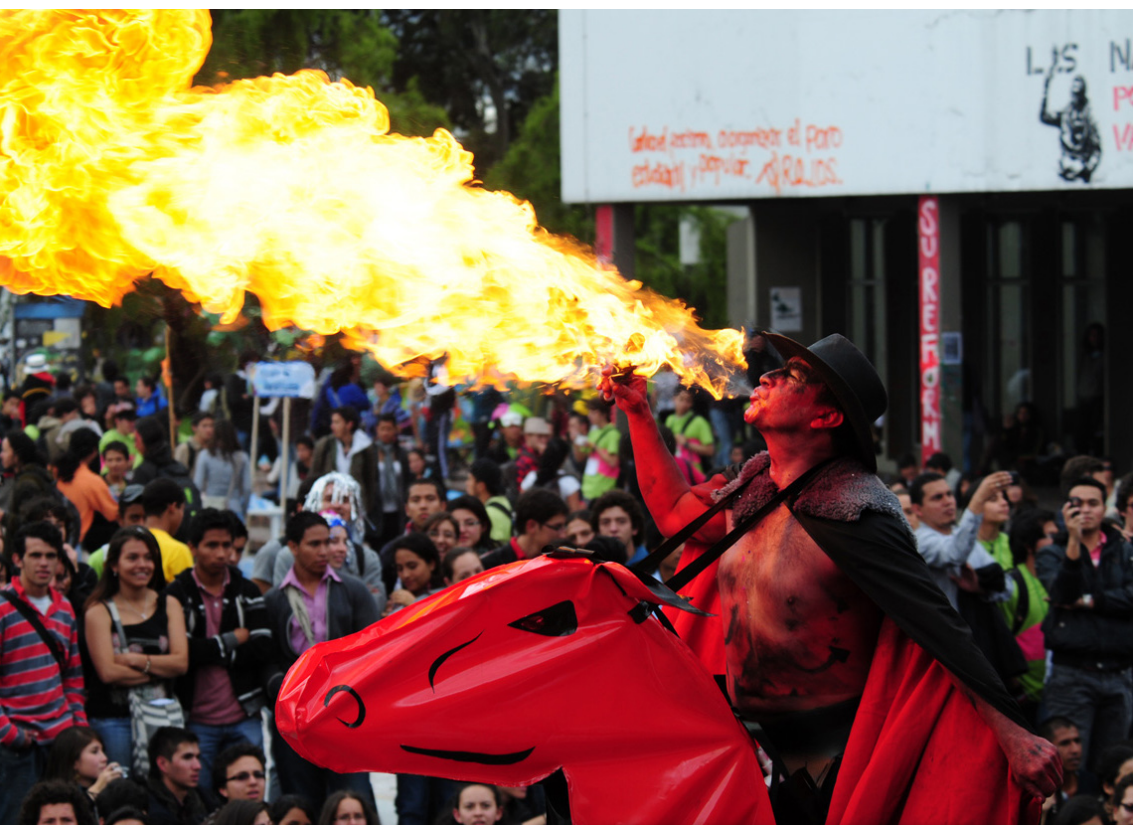

Figura 2:

Carnaval

Estudiantil

2011,

Universidad

Nacional de

Colombia,

fotografía:

Javier de

la Cuadra

Archivo:

Revista

Contestarte

Abello Banfi (2005, p. 158): “El carnaval es la fiesta popular por antonomasia, donde cada persona se transforma en protagonista y si no es la más alegre, sí la más libre".

Ahora, según el análisis textual, según la "lectura" etnográfica, el carnaval es un ambiente colmado de significaciones (GUIMAREY, s. f., p. 1). Una mezcla de infinidad de elementos simbólicos sobrecarga la escena festiva, cada detalle, expresión y símbolo definido posee una función particular dentro de la escena (Figura 2). Las carrozas, la participación de las reinas, la risa, la algarabía, la mesura y la desmesura y la muerte (representada en el Pericles, en el Joselito, el fin de la fiesta) poseen una carga simbólica que refleja una carga emocional, un sentimiento colectivo. Saltando al plano lingüístico, el carnaval es un oxímoron, una contraposición entre "lo pagano y lo moral; lo correcto y lo incorrecto; lo que es y lo que no es" (VALERo y cols., 2011, p. 17). Esto se puede leer en este hecho cultural: todos tienen la posibilidad de ser todo y a la vez nada, el carnaval es un mar de significación.

Así pues, teniendo como base esta línea de acercamiento al carnaval, lo que sigue es un acercamiento a los significados del carnaval estudiantil de los años 20 y 30 en la ciudad de Bogotá. Partiendo de su análisis histórico, reviso su simbología específica y su impacto en la transformación de la ciudad y del país. 


\section{DIMENSIÓN SIMBÓLICA DEL CARNAVAL ESTUDIANTIL DE LOS AÑOS 20 Y 30 EN BOGOTÁ}

¡Estudiantes!... Alcemos la bandera / que ilustraron los próceres de ayer, / y florezca a sus pies la primavera / del amor renovado en nuestro ser. / iY echen a vuelo el nombre de estudiantes, / en bronces de romántica emoción, / los que lo son, los que lo fueron antes; / los que por suerte tienen de estudiantes / para toda la vida el corazón! ${ }^{1}$

Revienta el 21 de septiembre de 1921 la primavera, con el equinoccio en el hemisferio sur, y junto con ella la primera Fiesta del Estudiante de la Universidad Nacional de Colombia. Así, gracias a "la aproximación poderosa de la primavera, que impregna placenteramente la naturaleza toda, despiértense aquellas emociones dionisiacas en cuya intensificación lo subjetivo desaparece hasta llegar al olvido de sí" (NIETZSCHE, 2005, p. 45). La primera semana de la primavera, sin embargo, representaba para los bogotanos algo muy diferente a un periodo de regocijo. Colombia, por estar ubicada cerca de la línea ecuatorial, no tiene estaciones, y septiembre representa más un mes de lluvias que otra cosa. ${ }^{2}$ Así pues, en la Bogotá de los años 20, de calles despavimentadas, la fiesta estudiantil se celebraba en medio de lluvia, barro y serpentinas.

El programa de la Fiesta del Estudiante se complementaba con gran cantidad de actividades, tales como competencias de natación, concursos de poesía, batallas de flores que se extendían por horas, exposiciones de caricatura, la famosa becerrada estudiantil en el Circo de San Diego, ${ }^{3}$ bailes suntuosos, la coronación de la reina y el carnaval de disfraces. Se celebraba el renacer de la naturaleza a la par que se enaltecía el espíritu joven, renovador y creador.

Inundaban las calles de Bogotá los estudiantes, las serpentinas y el confeti. El desfile de carrozas salía de la Plaza de San Agustín hacia el norte y luego se detenía en la Plaza de las Nieves (calle 20 - carrera 8a) para tomar la calle más significativa de la ciudad: la Calle Real, hoy conocida como la carrera séptima. Allí la multitud buscaba el regreso hacia el sur.

La bandera de la Federación de Estudiantes, de color verde y blanco y uno de los elementos simbólicos más importantes de la Fiesta del Estudiante, recorría la ciudad y era gratamente recibida en cada una de las facultades de la universidad, que en ese entonces se encontraban distribuidas en varias partes del centro de Bogotá. El recorrido de la bandera partía de la Casa del Estudiante, en la que se gestaban las propuestas generadoras de cambio en la universidad y en el entorno social de la época. 


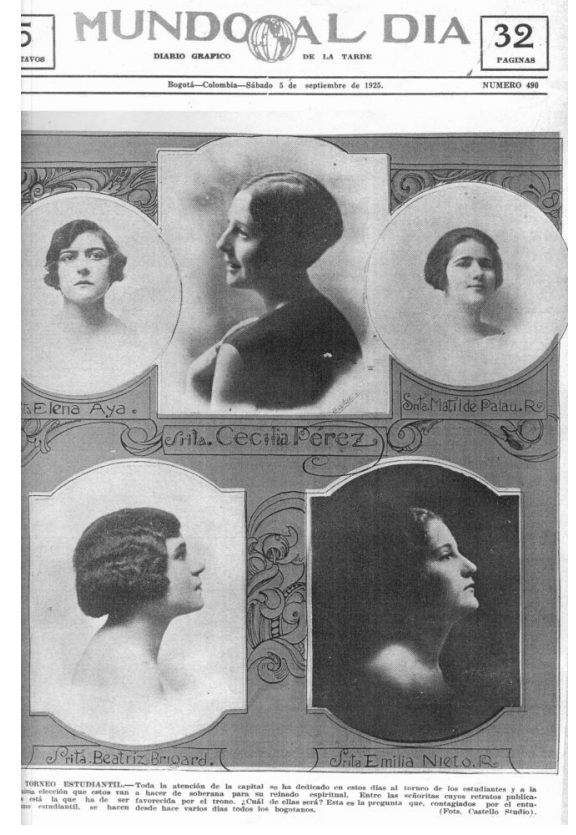

Figura 3: Periódico Mundo al día, 5 de septiembre de 1925, archivo: Revista Contestarte
Las reinas (Figura 3), en el momento de la coronación, podían realizar la "promulgación de sus 'órdenes reales', una especie de Bandos" (GONZÁLEZ, 2005, p. 119);

recibían la potestad de gobernar, podían nombrar embajadores y funcionarios, etc., y presentar un pliego de peticiones ante el Congreso de la República. Este nombramiento, aunque simbólico y burlesco, era un medio contundente de transformación del entorno. Lo más importante del carnaval siempre será su inversión social. Los concejales, alcaldes y demás mandatarios renunciaban a sus labores y permitían que el pueblo tomara el mando. En este caso específico una mujer líder acompañaba, durante los días de fiesta, al presidente y decidía el futuro del país:

la entrada de la mujer a la fiesta acabó traduciéndose en la reforma universitaria que le dio el vuelco a unas escuelas hasta entonces mantenidas dentro del rigor de un seminario eclesiástico (...). La verdad es que, bailando, cantando y tirando serpentinas, vino a cumplirse la reforma radical de la universidad (ARCINIEGAS, 1996, $\S 7)$.

El desfile se podía observar desde los balcones espléndidamente decorados. Las personas podían desde allí arrojar claveles, serpentinas y confeti, y mirar con detalle las carrozas y los disfraces. Las aceras se llenaban de espectadores de todas las escalas sociales. Los carros de la capital se movilizaban todos, haciendo parte de carrozas o llevando afanosos espectadores. Las mujeres hacían su aparición vestidas de manolas o gitanas 
Figura 4: Periódico Mundo al día, septiembre de 1925, archivo: Catalina Bohórquez Mendoza

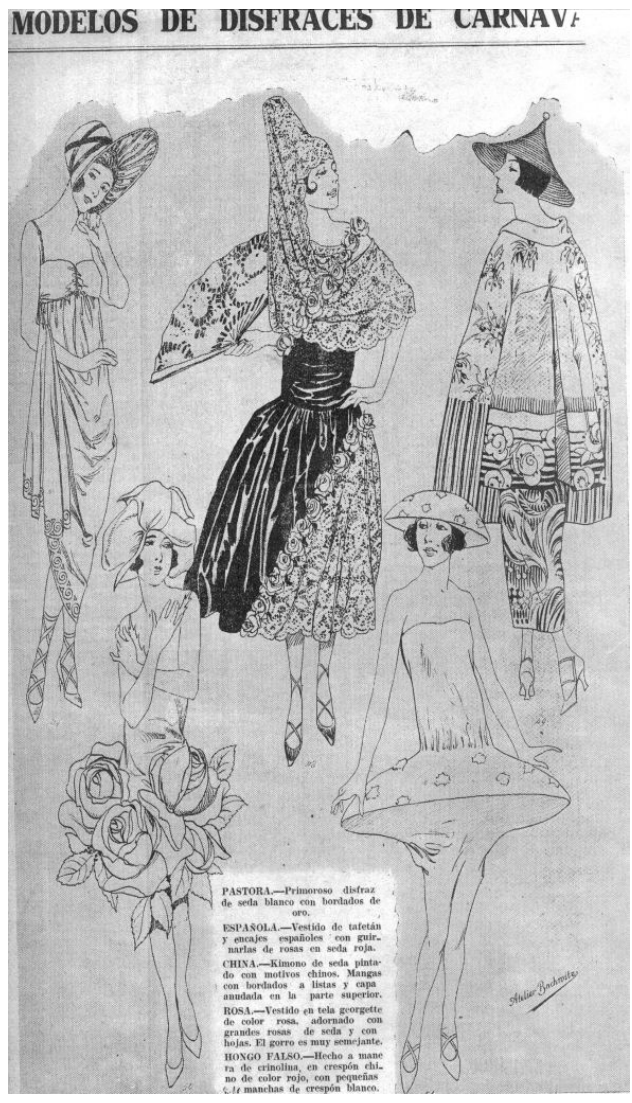

(Figura 4), y los demás hacían parte de las comparsas y carrozas. Era una expresión de nuestra interculturalidad, de la mezcla entre nuestras raíces españolas y lo autóctono.

Los carros y comparsas más representativos eran galardonados y reseñados en los más importantes diarios, cada carro poseía gran riqueza simbólica. Las carrozas de los "Caballeros Templarios" y del "Trasteo de un rico", así como las comparsas de los "Reyes y los Caballeros de la Baraja", "Los Highlanders Escoceses", el "Nido de los Búhos", "los Caballeros del Ku-Klux-Klan”, "Los Árabes", "Los Gitanos", "Los Mosqueteros", entre otras tantas, fueron consideradas las mejores representaciones artísticas. La representación de la famosa "Loca Margarita", habitante de la calle de la ciudad de Bogotá y recordada por su espíritu liberal y su clara aversión a los godos, era también notablemente resaltada (Cf. GONZÁLEZ, 2005).

Los estudiantes, que habían cambiado sus libros y cuadernos por el antifaz y los disfraces, finalmente levantaban a Pericles carnaval para celebrar su muerte, su robo y fusilamiento y realizar su entierro. El gran muñeco de algodón, guardado todos los años frente a la Facultad de Medicina, en la Plaza de los Mártires, "sirvió para darle un vuelco no solo a la vida estudiantil, sino a todos los antecedentes del vivir bogotano, que hasta entonces había sido 
completamente cuando la Federación de Estudiantes acepta su inminente escisión y la reina, como su representación femenina, se ve envuelta en sucesos que se alejaban completamente de sus objetivos. La protesta de los trabajadores de la empresa cervecera Germania, cuyo interés era presentar la exigencia de transformación social, terminó con la renuncia de la reina de los estudiantes. Pues Mariana Kohn Olaya, la hija del dueño de la empresa cervecera y reina estudiantil, fue acusada de disolver la huelga al ingresar a la policía en su carro, en vez de apoyar a los trabajadores que se encontraban allí en huelga. Así, en medio de inconvenientes políticos y sociales, la Fiesta del Estudiante fue desterrada del gris bogotano.

El carnaval, en el marco de la celebración del día del estudiante, se presentó, entonces, como vinculado al movimiento estudiantil. Además de música y disfraces constituyó un elemento de reflexión política y social. Por medio de la fiesta se logró la transformación de su entorno, la posibilidad de la cátedra libre y, finalmente, la llegada de la mujer a la academia a partir de su elección como reina y representante de la lucha estudiantil. El carnaval fue un espacio para la reivindicación de los derechos de los estudiantes y, en 1926, para la discusión sobre la posibilidad de la construcción de una ciudad universitaria.

\section{LA MÚSICA DE CARNAVAL ESTUDIANTIL, OTRA DIMENSIÓN SIMBÓLICA}

La música como uno de los elementos característicos de los carnavales, habla de situaciones, circunstancias, costumbres, personajes. Es una dimensión simbólica fundamental del carnaval, pues exhibe en notas musicales los sentimientos de los compositores, las situaciones más representativas y los momentos de júbilo de la fiesta; la música es la protagonista y la acompañante de la fiesta, la iniciadora y cómplice de la risa.

El carnaval estudiantil de los años 20 y 30, en esta dimensión simbólica, exploró más allá de la música de las calles y la puesta en escena. Se conoce la existencia de más de una docena de partituras en ritmo de fox-trot, milonga, tango-danza, rag-time, el two-step; una serie de canciones dedicadas al carnaval, los estudiantes, las reinas y damas ilustres de la época. Estas obras musicales se encontraban compuestas, en su mayoría, para piano, violín y voz y sus ritmos eran foráneos, no eran propios del país sin traídos por los compositores en sus viajes y explorados como medios de representación de sucesos nacionales. 
El libro Carnestolendas y Carnavales en Santa Fe y Bogotá (GonZÁLEZ, 2005) enuncia la existencia de unas partituras dedicadas al carnaval estudiantil y hace referencia a la investigación de Jaime Cortés Polanía sobre la música nacional y popular colombiana publicada en el periódico Mundo al día. El grupo Contestarte, de la Universidad Nacional de Colombia se dio a la tarea del hallazgo y puesta en escena de estas partituras, algunas de ellas aparecieron en el Banco de partituras de la Biblioteca Nacional de Colombia y otras tantas se hallaron luego de revisar el periódico Mundo al día. Sábado tras sábado un músico profesional o aficionado tenía la posibilidad de publicar una partitura en el periódico Mundo al día que, de algún modo, hiciera alusión a las noticias del día a día; el carnaval estudiantil, como una de las actividades más importantes del año, también recibía este merecido homenaje.

Las partituras halladas fueron las siguientes: 1. "Himno del Carnaval", H. L Uribe y Jaime Robledo, Septiembre de 1924 / 2."Emilia I", Alberto Collins, Tango, Septiembre de 1925 / 3. "Emilia II", Alberto Urdaneta, Marcha triunfal, Julio de 1926 / 4. “Olga I”, Francisco Cristancho, Tango-milonga, Marzo de 1928 / 5."Reina Mora", Alberto Urdaneta, Danza para piano, Junio de 1928 (Figura 6) / 6."Beatriz", Gustavo Acosta, Tango para piano, Junio de 1928 / 7. "Himno a la bandera", Alejandro Wills y Diego Uribe, Agosto de 1928 / 8."Inesita", Jerónimo Velasco, Pasillo para piano, Septiembre de 1928 / 9."Su Majestad", Lucho Bermúdez, Pasillo para piano, Enero de 1929 / 10."Teresita”, Fortunato Beleño, Pasillo sentimental para piano, Abril de 1929 / 11."Loco Carnaval”, Guillermo Quevedo, Pasillo fiesterito y de bola a bola, Julio de 1929 (Figura 7) / 12."Inspiración”, Carlos Escamilla, Pasillo para piano, Septiembre de 1929 / 13. "Ofrenda Real”, Rafael Vélez, Two-step para canto y piano, Septiembre de 1929 / 14. “Cecilia”, Juan Salas, Rag-time para piano, Septiembre de 1929 / 15.“Maria Teresa I", Marcel DaCapo, Carnavalesca para piano, Octubre de 1929 (Figura 8) 16."María Teresa”, Benjamín Romero Santos, Danza-tango para piano, Noviembre de 1929 / 17.“Carnavalesco”, Emiliano Gonzalez, Pasillo colombiano, Julio de 1930 / 18.“Olga Cecilia”, Humberto Gomez, Pasillo colombiano, Noviembre de 1930 / 19.“"Teresita”, Luis A. Calvo, valse para piano, Abril de 1931

El espíritu del carnaval estudiantil, y de sus elementos simbólicos, fue resumido en las estrofas de "El himno del Carnaval", con letra de Jaime Robledo y música de la señorita H. L. Uribe. Fue publicado en 1924 en el periódico Mundo al día, para inaugurar su página musical: 


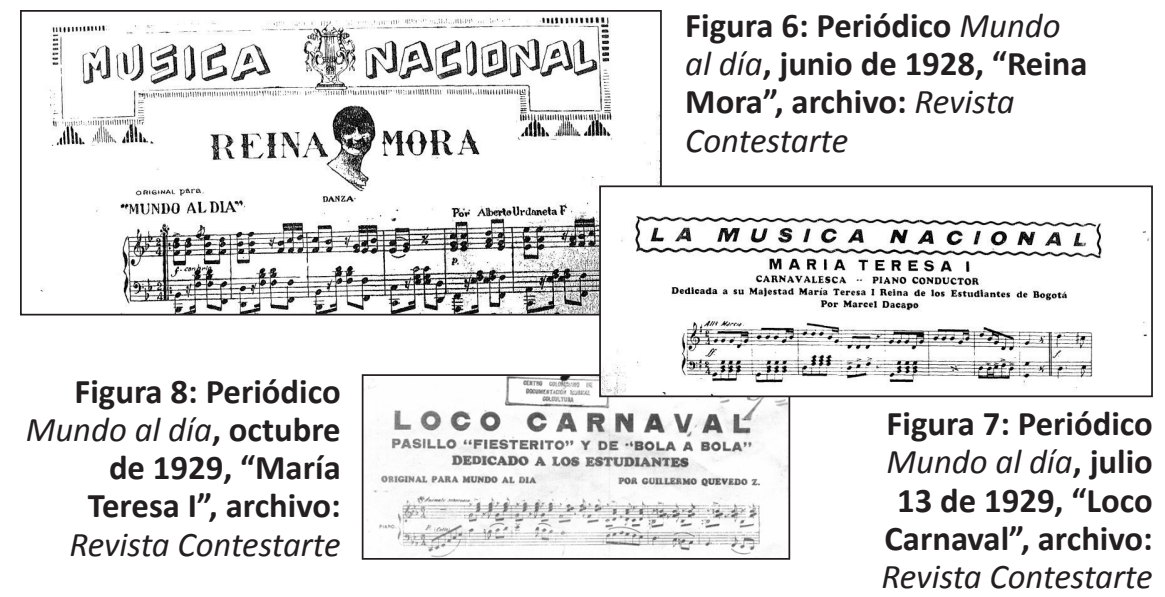

Lejos de libros y profesores, / mucho más lejos del bien y del mal, / entre sonrisas mujeres y flores, / llega el presagio del Carnaval. / Las chicas, que antes eran esquivas, / Pues nuestros no eran ni capa ni frac, / entre nuestras redes quedan cautivas, / de nuestra flema de Bergerac. / En nuestro empeño sólo admitimos / el magisterio de Omar Kayam / que, en una copa, sapiencia y vino, / supo, felices, involucrar. / Y así entre corte de luz y amores / y muy distantes del bien y del mal, / brotara en medio de entre las flores / la flor burlesca del Carnaval.

Y así como las serpentinas, las flores y las mascaradas recibieron por medio de esta obra musical su merecido homenaje, partituras como "Ofrenda Real”, “María Teresa I", “Emilia I”, “Beatriz", “Olga I", “Reina Mora” y otras tantas, enaltecieron la participación de la mujer en la fiesta estudiantil, como reina y representante de los estudiantes, pues más que bellas eran influyentes líderes políticas.

\section{CONCLUSIONES}

El carnaval como hecho cultural, entonces, se muestra como un enjambre de significaciones. La representación de la realidad social existente, expresada en un sistema simbólico, es transpuesta por el sistema del carnaval. Así pues, los negros pueden ser blancos, los ricos pobres, los campesinos gobernar y los gobernadores hacer el rol de súbditos. Se expresa, entonces, 
en el carnaval una realidad deseada de manera crítica. Estos juegos simbólicos posteriormente se consolidarán como propuestas de cambio social, enmarcadas en la tolerancia, el respeto y la equidad.

Así pues, desde el análisis textual del carnaval afloran una cantidad de símbolos que tienen un importante impacto a nivel social. En el caso del carnaval estudiantil, la aparición del Pericles que invita a la fiesta, la formalidad de la entrega de la Bandera y, lo más importante, la elección de la reina de los estudiantes, son elementos fundamentales de este hecho cultural, que terminó en una reforma universitaria que se reflejó en el país.

De este modo, el rompimiento de las clases sociales y la posibilidad de que una mujer se encuentre al mando de la nación (en una época en la que no tenía la posibilidad de estudiar, ni mucho menos el derecho al voto) son muestras de esta transformación de los sistemas simbólicos establecidos mediante la risa, la algarabía, la mesura y la desmesura, en dos palabras: el carnaval.

En el carnaval estudiantil, por medio de juegos, música, batallas de flores interminables y disfraces, los bogotanos transformaron esa realidad social expresada en su sistema simbólico cultural. Más allá de las serpentinas, la transformación social fue el trasfondo de este enjambre simbólico. Más allá del carnaval, de los disfraces y de la catarsis colectiva, lo cierto era que bajo este pretexto se estaban generando cambios importantes. Los estudiantes, inmersos en este inconsciente colectivo, generaron propuestas importantes para la nación y realizaron la transformación de la educación colombiana.

Desde la perspectiva de la descripción densa, entonces, el carnaval constituye en un sistema simbólico que trae como consecuencia una propuesta de transformación social. A partir de la lectura simplista del carnaval, éste es solamente rumba, gozadera, colores, disfraces y música, entre otras cosas. Hacer una lectura densa de este hecho cultural es de vital importancia para reconocer su estatus simbólico y su propuesta transformadora.

\section{BIBLIOGRAFÍA}

ABELLO, J. El Carnaval, una actividad saludable. Huellas, 2005, p. 158-162.

ARCINIEGAS, G. (30 de septiembre de 1996). El día del estudiante. Obtenido de http://www.eltiempo.com/archivo/documento/MAM-517462.

CUCHE, Denys. La noción de cultura en las ciencias sociales. Buenos Aires: Nueva visión, 2002.

GADAMER, Hans-Georg. Verdad y método I. Salamanca: Sígueme, 1977. 
GEERTZ, Clifford. Intepretación de las Culturas. Madrid: Ed. Rev. Editorial Gedisa. 2005.

GONZÁLEZ, M. Carnestolendas y Carnavales en Santa Fe y Bogotá. Bogotá: Intercultura, 2005. . (coord.). Fiestas y nación en América Latina. Bogotá: Intercultura, 2011.

GUIMAREY, M. (s. f.). El carnaval como práctica social espectacular: perspectivas para una revisión de la historiografía tradicional del carnaval. Recuperado del sitio web: http://zambrarte.blogdiario.com/img/carnaval.pdf.

LÉVI-STRAUSS, C. Introducción a la obra de Marcel Mauss. Mauss. M. Sociología y antropología. Madrid: Tecnos, 1979.

MONTENEGRO, A. (2008). Carnaval. Recuperado del sitio web: http://www. elespectador.com/opinion/columnistasdelimpreso/armando-montenegro/ columna-carnaval

NIETZSCHE, F. El Nacimiento de la Tragedia. Madrid: Alianza, 2005

PAULUS, J. La función simbólica. Barcelona: Herder. 1975.

RESTREPO, G. Arte, fiesta, literatura. El sagrado oficio de la cultura. Bogotá: Universidad Nacional de Colombia, 1997.

RIVAS, R. Metáfora y mentira. Aproximación al concepto de cultura en Nietzsche. Intersticios. Año 13, n. 29, 2008

SEWELL, W. En: BONNELL, Victoria E.; HUNT, Lynn (eds.), Beyond the Cultural Turn. Berkeley/Los Ángeles: University of California Press, 1999, p. 35-61.

VALERO y cols. Carnavales orígenes y esencias. Revista Contestarte, 10, 2011, p. 14-19.

\section{NOTAS}

1 Fragmento de la "Canción del estudiante", en su celebración en Argentina. Esta obra fue compuesta por Francisco García Jiménez, Ernesto Galeano y Carlos Guastavino.

2 Este inconveniente climático significó en 1926 un cambio de fecha de los fastos. A partir de ese entonces, el carnaval se realizaba por los días del 12, 13 y 14 de julio.

3 Actualmente, la Plaza de Toros de Santamaría de Bogotá.

Catalina Bohórquez Mendoza es filósofa de la Universidad Nacional de Colombia. Especialista en Gerencia y Gestión Cultural de la Universidad del Rosario. Directora de la Revista Contestarte de la Facultad de Ciencias Humanas de la Universidad Nacional de Colombia, editora y miembro de la junta directiva de la Corporación de Estudios Interculturales Aplicados Intercultura Colombia. 
